\title{
PRODUÇÕES SIGNIFICANTES: \\ O DESENHO E A ESCRITA DE UMA "MENINA"
}

\author{
Daniela Waldman Teperman \\ Ilana Katz Zagury Fragelli
}

$[\square$

á um tempo em que o sujeito ainda nào selou sua estrutura. É um tempo no qual pode-se pensar em uma intervençào na direçào de sua constituição. Um tempo fundamentalmente diferente daquele em que a estrutura do sujeito já está decidida e é a partir desta diferença que a intervenção precisa ser concebida.

Em outras palavras, a partir do pensamento estruturalista, e se quisermos assumir qualquer coerência com esse, precisamos ter claro que há o tempo em que o sujeito se estrutura, há o tempo em que são feitas as primeiras inscriçòes no aparelho psíquico. Há o tempo da infância, em que o sujeito deve se apropriar das marcas significantes inscritas pelo Outro.

Dizer que a infância é o tempo da constituição da estrutura, ou da "estrutura sem selar", como sublinha Coriat (1997), não nos furta a possibilidade de construir uma hipótese diagnóstica a respeito dos pequenos que são trazidos ao tratamento.

O diagnóstico na infância assume uma importância radical no sentido em que, ao se dar sobre um tempo de estruturação, pode reconhecer a direçào que esta toma e dar à intervençào clínica a possibilidade de agir no tempo mesmo da formação da estrutura, e quem sabe, mudar seu rumo, ou ao menos, alicerçar sua rota.

Desse modo, no Lugar de Vida, trabalhamos com uma hipótese diagnóstica. Esta é formulada no decorrer do tratamento e é suscetível a modificações a partir do mesmo. É impor-

- Psicóloga; membro da equipe do Lugar de Vida - Psicóloga; colaboradora do Lugar de Vida no Projeto Educação Terapêutica em atendimento individual 
tante que seja assim, que possamos rever a hipótese diagnóstica a partir dos efeitos do tratamento, ao mesmo tempo em que esta é fundamental na direçào deste último. Como propomos o diagnóstico na infância, se lá ainda nào foi selada a estrutura do sujeito?

Começamos a responder essa questào citando o título de um livro organizado por Laznik-Penot (1991): "O que a clínica do autismo pode ensinar aos psicanalistas." Aqueles que se aventuram por suas páginas possivelmente concordariam que não poderia ser outra a marca na sua capa. Seus autores explicitam toda uma série de questòes que, levantadas a partir da clínica com crianças autistass, ensinam aos psicanalistas os meandros, e por que não dizer, os tempos da instalaçào do circuito pulsional, explicitam a delicadeza dos primeiros encontros com o significante e seus efeitos e falam dos impasses e tropeços que podem ocorrer no tempo pré-especular, nos primórdios da instalação do sujeito.

Sabemos que a neurose, a psicose e o autismo (1) designam modos particulares de efeito do significante no corpo do infans. Se pudermos nos debruçar sobre esse modo, em cada caso, poderemos atuar sobre seus efeitos.

Passaremos a discutir os efeitos do significante no corpo de uma criança a partir das inscriçoes mais primordiais que, através da escuta, pudemos localizar é sobre elas intervir. Sibele - nome que escolhemos para nos referirmos a esta criança - é atendicla na PréEscola Terapêutica Lugar de Vida há trás anos, desde os seus seis anos de idade. Freqüenta as atividades grupais da montagem e, recentemente, iniciou um atendimento individual em educação terapêutica. Sua màe, além de freqüentar o grupo de pais, é escutada individualmente por um profissional que chamamos de "referência" e que, muito resumidamente, é o responsável por coletar os significantes aos quais cada família é sensível.

Esse artigo é uma síntese realizada por dois profissionais que escutam sibele e que, por sua ve'z, estào sustentados pela rede de escuta que a instituiçào produz.

Inicialmente, o que nos chamou a atença em Sibele foi o fato de que ela se movimentava ininterruptamente. Quando as mãos seguravam algo, os olhos já estavam em outro lugar. Sibele não olhava, não fixava a visào, seu olhar nos atravessava (havia uma evitaça ativa). Era um olhar indireto; ela reagia virando-se ou afastando-se quando uma pessoa se aproximava, o que demonstrava que percebia quando era observada.

Em relação ao olhar de Sibele neste primeiro momento, é interessante o comentário de Jerusalinsky (1993) sobre o olhar do autista: "O autista tem algo que eu chamo de 'alerta indireto' ou 'vigilância oblíqua'. Um autista nào olha diretamente, mas ele está sempre vigilante da posiçào do outro para manter a distância necessária para recompor incessantemente a posição de exclusão que the garante sua condiçào de ser". O autor, do fazer esta reflexão, poderia muito bem estar descrevendo Sibele neste primeiro momento. 
Ainda descrevendo Sibele por ocasião do início do tratamento, observamos que falava algumas palavras soltas mas não se dirigia ao outro. Sua fala era ecolálica e as palavras eram pronunciadas com entonação de voz alterada (modalizaçào tonal). Era freqüente que em suas brincadeiras imitasse apresentadoras de televisão cantando e dançando.

Poderia a agitação psicomotora de Sibele ser tomada como um fenômeno elementar característico da psicose? Os fenômenos elementares são manifestacòes independentes e caóticas das funçòes psicológicas. Estes se manifestam de modo autônomo em relaçào ao sujeito, demonstrando uma redução da personalidade a seus componentes mínimos, daí receber este nome (Jerusalinsky, 1993). O delírio motor equivale ao delírio propriamente dito, encontrado em psicóticos adultos. Observamos em Sibele a manifestação de: delírio motor, ecolalia (fala não governada pelo campo da palavra) e mimese. A imitação das apresentadoras de TV é um exemplo disso. A mimese é uma movimentação imitativa na qual a criança procura construir uma significaçào, encontrar algum traço em que se reconheça.

A busca de sibele por um traço que a represente tornat-se patente no desenrolar do tratamento. Discutiremos longamente este ponto, que é o eixo do processo de subjetivação desta criança.

Neste atendimento, levando em conta que nào há nenhum indício que aponte para uma etiologia orgânica ou genética do quadro apresentado por esta criança, nos questionávamos acerca de seu diagnóstico. Tratava-se de um caso de autismo ou de psicose? O olhar - melhor dizendo: o nào-olhar de Sibele nos confundia. No entanto, após dois meses do início do atendimento, o olhar de Sibele sofreu uma alteraçào visível. Assim, a evoluçâo deste caso, os movimentos-efeitos do tratamento e a posição dos pais foram muito importantes na verificação de uma estrutura, presente nesta criança, levando-nos a levantar a hipótese de uma psicose nãodecidida.

\section{UM POUCO DA HISTÓRIA}

Maria, mãe de Sibele, é quem foi historizando e trazendo os significantes que "falam" de sua família.

Comparecia às primeiras entrevistas queixando-se. Inicialmente, as queixas faziam referencia ao corpo. Queixava-se de dores de cabeça, cansaço, gripe, etc. As queixas, somadas ao relato da gravidez e parto de Sibele, levavam-nos a pensar num quadro de depressão no qual as questòes a serem formuladas, por nào passarem pela palavra, manifestavam-se no corpo desta màe.

Chamam a atenção os aspectos da posiçào desta màe que se atualizam em Sibele. O real do corpo de Maria nos conta a respeito de sua impossibilidade de simbolização. É deste mesmo lugar que Sibele responde ao Outro, quando, como veremos a seguir, responde às emergências subjetivas com o real de seu corpo. Notamos ainda que há uma certa repetiçào/presentificaçào em Sibele do riso/gozo da màe.

Algo que emocionava sobremaneira esta màe era a referência a seu primeiro filho (neste momento com treze anos, filho de outro companheiro) que entregara para sua màe cuidar quando este tinha onze meses. Nesta época, Maria trabalhava e tinha que pagar uma creche, "nào ligou muito"(2) quando sua mãe o levou. Desde essa época o filho mora com a avó materna no Nordeste. Há algo situado neste primeiro filho da ordem de um luto não resolvido que retorna sempre que mencionado. 


\section{O PRIMEIRO SIGNIFICANTE: OS LUGARES...}

Sibele vive com o pai, a màe e a irmã mais nova. Todos dormem no mesmo quarto, na mesma cama (Maria relata que pretende construir mais um cômodo para as meninas pois neste em que dormem nào há espaço para camas separadas).

Maria passa a narrar diversas situações que explicitam uma certa indiscriminaçào nesta família em termos de lugares, funçòes. Relata que certo dia a filha mais nova dormiu em seu lugar na cama. Parece ficar irritada com este episódio, afirmando que o pai permite que isso aconteça e que é muito difícil quando "um fala uma coisa e o outro tira a autorizaçào". Nós nos perguntamos então: Quem é quem nesta família? Quem manda? Quem dorme com o pai?

Às voltas com esta confusão familiar, Maria começa a falar de seu marido. Até este momento, este pai/marido nào aparecia em seu discurso. Em Sibele também nào observávamos qualquer referência a este. Nem a presença nem a ausência do pai pareciam marcantes. Sua intervença na vida de Sibele parecia não ter grande peso. A partir deste momento começa a se delinear, lentamente, a construçào de um "lugar" de pai.

E a respeito deste pai, Maria diz: "Ele é preguiçoso, nào quer ficar com as meninas... bomem só serle para fazer. filho e pagar as contas... precisa dar atençào". Diz que conversou solre isso com as vizinhas e todas disseram que os maridos nào dào atençào.

É interessante que Maria vá checar com as vizinhas o que um pai deve fazer. De certa forma, parece desconfiar que há algo que nào opera em relaçào a este pai. Quando lhe diz que "deve dar atençào" parece dizer-lhe que precisa fazer algo mais. Aqui, faz sentido falarmos em função paterna, na qual o pai (ou qualquer outro, desde que exerça tal função) introduz a descontinuidade, o corte, entra como um terceiro na relação mãe-bebê. Observamos que até esse momento a relação de Sibele e sua màe era binomial, não havia lugar para um terceiro, um Outro. É interessante pensarmos que através da transferência (3) com a instituição, Maria coloca esta última em lugar de terceiro, de um Outro que pode fazer este corte. E é a partir deste lugar que devemos pensar os efeitos em Sibele.

A dificuldade em colocar "limites" (entenda-se lei, corte, descontinuidade, Nome-do-Pai) é patente nesta família. Vemos aqui, portanto uma mãe queixosa destas filhas "pirracentas" mas que ao mesmo tempo goza com elas. Se, por um lado, percebe que a falta não está colocada para sibele e que o pai precisa mudar de posiçào, por outro, ri quando Sibele "pirraceia" o pai. Relata, rindo, que quando o marido chega em casa, "Sibele apronta e ri do pai, parece que faz isso para irritar". Maria não só autorizat este "aprontar" como confirma a filha nesta posiçào. É curioso que Maria utilize a palavra "autorização", pois, por um lado, ela "autoriza" a "pirraça" e por outro, des-autoriza/ nàoautoriza a palavra do pai. Como veremos mais adiante, ao contar sobre o nascimento da filha, observamos que ela des-autorizou até mesmo a possibilidade de que aquela criança pudesse ser um menino, conforme o desejo do pai.

Este significante: "autorizar" pode ser facilmente associado a uma das tarefas que dizem respeito à funçào maternal, qual seja, a de transmitir/autorizar a palavra do pai. A funçào materna inclui os três registros: real, imaginário e simbólico. Ao dar à luz à criança, a màe 
está incluída no registro do real. Ao constituir () narcisismo da criança, libidizando-a e incrementando concomitantemente o seu próprio narcisismo, opera no registro do imaginário. E, por último, ao transmitir a palavra do pai para seu bebê, a màe opera no simbóli(c).

A màe de Sibele pôde operar nos dois primeiros registros descritos. Sibele, muito possivelmente, foi um bebê libidinizado, o significante "menina" que mais adiante verificaremos estar inscrito como um poss'vel traço em que Sibele pode se reconhecer - parece confirmar esta possibilidade. Agora, parece que esta màe falha em sua funçào simbólica, no momento de transmitir a palavra do pai.

\section{O REAL DO CORPO}

lim poucos meses de tratamento observamos movimentos significativos em Sibele. Conforme relatamos anteriormente, houve uma mudança qualitativa em seu olhar: da evitação ativa a um olhar dirigiclo, porém titubeante.

A primeira vez que sibele interagiu com um adulto foi através de um objeto. A coordenadora de uma das atividades se aproximou dela com um fantoche e surgiu aí um pequeno diálogo, no qual sibele pedia beijos - "dá bejo" ao fantoche. Foi o primeiro momento no qual sibele estabeleceu contato, parece que apenas o contato mediado era suportável. Podemos dizer que o fantoche nào demanda nada da criança. Sabemos que crianças psicóticas nào respondem, não perguntam, nào aceitam a demanda do Outro, mais que isso, nào a suportam, e é isso que torna selu contato conosco ainda insuportável.

Na semana seguinte a esse episódio, Sibele teve febre. A mãe diz que esta febre deve ter sido "emocional", pois nào havia outros sintomas. Parece que o olhar da màe está reconhecendo um sujeito... A febre é manifestação de um efeito de algo que foi excessivo e passou pelo corpo de sibele no plano do real, algo que ainda nâo pôde ser simbolizado. Lembremo-nos de sua mãe que em um primeiro momento trazia suas questòes no real do próprio corpo.

Mais adiante há um outro episódio significativo. Sibele escapa da sala de atendimento e entra numa outra sala na qual uma funcionária da limpeza the pergunta seu nome. Sibele responde algo à funcionária, embora não possamos compreender o que diz. Depois deste episódio, retorna à sala e começa a se sentir mal, encolhe-se e vomita. Parece que o contato direto com o Outro ainda lhe é insuportável.

\section{O SIGNIFICANTE "MENINA"}

No início, Sibele tinha o hábito de desenhar em seu próprio rosto e de fazer rabiscos circulares em folhas de papel. Foi possivel a um profissional reconhecer naquela garatuja o desenho do rosto de uma menina e nomeá-lo. Sibele passou a fazer aquele rosto quando the solicitavam que desenhasse uma figura humana. Reconhecia ali a significaçào atribuída pelo adulto e começou a detalhar mais sua produçào. Os rabiscos circulares definiram-se nitidamente: olhos, boca, nariz, orelhas, cabelo, o esboço de um corpo já the é possivel.

Paralelamente, Sibele foi construindo contorno para seu próprio corpo, riscava-o na pele; procurava-se no espelho, voltava a fazer marcas com caneta ou tinta sobre o rosto. Contornava o rosto, separava com outro contorno a boca, e mais outro risco destacava seus olhos. Nesses momentos diante do espelho um traço passou a aparecer insis- 
tentemente na testa de Sibele bem como no lugar correspondente na imagem virtual. Optamos por nos referir a este traço como "cobrinha".

Hoje dispomos de recursos para compreender o que ocorreu na atribuiçào do significante "menina". Poderíamos nos perguntar o que possibilitou que Sibele se reconhecesse neste significante, ou o que levou este profissional a nomear sua produção com o significante "menina" e no com qualquer outro, como boneca, criança, etc. Começaremos pela primeira parte da questão. Inicialmente atribuíamos "menina" aos investimentos maternos, que consistiam em dedicar-se à roupa, e, especialmente, aos cabelos de Sibele.

Recentemente, Maria - em uma conversa informal - contou-nos que desconhecia o sexo de Sibele até seu nascimento. No entanto, estava certa de que seria uma menina. Essa certeza se opunha claramente ao desejo do pai: um menino. Este chegou a fazer apostas no bairro onde mora de que o bebê seria um menino. Quando Sibele nasceu - uma menina - cumpriu-se a fantasmática da mãe, que desalutorizava o pai como participante desta concepçà, "ele nào sabe fazer menino", o que situa sibele como resultado da vitória e do desejo da màe em contraposiçà ao desejo expulso do pai. Sibele é filha cla màe. Como veremos mais adiante, a "menina" nào tem o nome do pai.

A partir destas informaçoes pudemos ressignificar um ato que Sibele repete insistentemente: cortar os cabelos. Estaria em busca do olhar do paii? Ou contestando o investimento da màe no objeto menina? En que cadeia este significante se insere?

O investimento de Maria nos cabelos e vestidos de Sibele vem a confirmá-la no lugar de objeto para o gozo da màe. Há uma inscriçào que situa sibele fora do campo do autismo mas que a aprisiona na fantasmática da màe, situando-a neste momento como uma criança psicótica.

Em carta à Jenny Aubry, Lacan formula que uma criança implicada como objeto do fantasma materno, realiza a presença deste objeto, e, ao substituí-lo, cumpre a funçào de impedir o acesso da màe à sua verdacle, e imprime a exigência de ser protegida. Mas é mesmo Lacan quem marca que há diferentes níveis de subordinação ao fantasma materno: "Em resumo, a criança, na relação dual com a màe, the dá, imediatamente acessivel, o que falta ao sujeito masculino: o objeto mesmo de sua existência, que aparece no real, disso resulta que na medida do que ele apresenta de real, acha-se oferecido a um maior subordinamento no fantasma." (grifo nosso)

No lastro dessa colocaçao, pode-se entender que nem toda criança implicada como objeto do fantasma da màe tem como único destino a psicose, pois há uma questào relativa ao grau possivel de realizaçào do objeto do fantasma. Ainda assim, presa como objeto deste fantasma, sibele nào tem condiçoes de se apresentar como sujeito barrado. 
Não podemos nos esquecer que resta ainda uma questão por responder, ou seja, o que levou o profissional da instituiçào a perceber, e nomear naquele desenho tão primeiro - já que vieram outros mais elaborados - uma menina. Seguramente trata-se de algo da ordem do inconsciente sustentado na rede de escuta que se constrói nas diversas instâncias da instituição. Em tantas atribuiçòes possíveis, esta ressoou.

\section{REPRESENTAÇÃO}

A partir desta nomeação Sibele foi traçando um caminho no eixo da representaçào. Incluiu no desenho da menina a marca que fazia em seu próprio rosto: a "cobrinha". Logo passou a usar este traço para marcar a sua presença na Chamada. A Chamada é uma atividade, realizada todos os dias no Grupo Educacional (um dos enquadres oferecidos pela montagem do Lugar de Vida), que consiste na assinatura do nome feita de próprio punho pelas crianças ao lado daquele que já está escrito em letra de forma pelo coordenackor. Kupfer (1997) sublinha: "Nào se trata apenas de ensinar a uma criança seu nome e o modo de escrevê-lo, esperando que ela o utilize tão somente em sua comunicação. Aqui, espera-se que o nome represente o sujeito, e se torne um significante, singularizando-o. Ou seja, que o designe, como único personagem a portálo."

Também durante as atividades do grupo educacional, quando a proposta era recortar palavras que começassem com a letra $\mathrm{A}$, fomos surpreendidos por Sibele, que, na 'Hora da Chamada' passou a assinar seu nome com uma seqüência de três letras A. Enquanto escreve, ela diz: "Si-be-le", representando com cada uma das letras A uma sílaba.

Em outra atividade, em que se desenhava o contorno dos corpos das crianças em tamanho natural no papel craft, um dos coordenadores, ao ajudar sibele a colocar uma roupa no desenho já feito, enfeita a produçào com uma longa "cobrinha". Ela toma a caneta da mào do profissional e se pòe a cortar cada uma das saliências do desenho, formando então uma longa seqüência de letras A. Desde entào, passa a escrever seu nome na Chamada e também a assinar suas produçoes, mantendo juntas as letras $\mathrm{A}$, encadeadas como fazemos na escrita cursiva.

O processo de aproximaçăo ao universo da escrita realizado por Sibele permite que sejam defendidas algumas hipóteses no âmbito de sua constituiçào subjetiva. Sibele transformou sua marca em letra. De posse do conhecimento ofertado, que poderia funcionar como mero instrumento para a comunicaçao, produziu um deslizamento significativo no modo de se representar. No aprèscoup pode-se entender que, desde os primeiros rabiscos circulares ela já buscava uma forma de representar-se. 
O movimento da criança conta que foi produzido algo da ordem de uma inscriçào. A partir da escuta, o desejo materno pôde operar para delimitar bordas, fazer cortes com a introdução de significantes que se inscreveram no corpo da criança (Stefan, 1991). No lastro desses significantes inscritos, encadeamentos foram possíveis: o desenho e a escrita.

Supòe-se que a escuta da màe, no primeiro tempo do trabalho, tenha sido fundamental para que sibele fosse incluída em seu "campo de visào". Àquela mãe foi possível um giro de posição, de maneira tal a incluir essa filha de um modo específico em sua fantasmática. Sibele, agora, pode prosseguir na constituiçào de sua subjetividade e para tal, o significante "menina" é seguramente um eixo, é um significante central que vai incluindo cada vez mais elementos, que vai se encadeando, pouco a pouco, a novos significantes.

Sibele sempre escreve, escreve em tudo e quase tudo que fala. Em alguns momentos avisa que vai escrever $e$, com a caneta em punho, diz: "Escrever", e segue silabando as palavras que põe no papel. O resultado de sua escrita é sempre uma coleçào de letras A que podem estar mais ou menos organizadas. É importante ressaltar que o que ela escreve sobre a marca da letra A pode nào ser o seu próprio nome. No âmbito da leitura, atividade para qual também se dedica, é capaz de ler logotipos e reconhecer marcas.

Até aqui, o trabalho tem como eixo a introduçào da diferença no interior da produção de Sibele. Não interessa ensiná-la a escrever pelo artifício da apresentaçào das outras letras do alfabeto, mesmo que acreditemos em sua capacidade de executar tal tarefa. Por que? Porque acreditamos que nào se trata de travar uma batalha para que Sibele saia fazendo da escrita um instru- mento de comunicação. Que funçào teria essa comunicação sem que o sistema de diferenças esteja instituído? Sem que as coisas possam ter a marca de sua singularidade? Sem que o outro possa assumir o papel de interlocutor reconhecido sob a marca de sua singularidade? Interessa-nos entào, que Sibele possa usar a escrita como instrumento para situar-se, com o maior grau de propriedade possível, na linguagem.

Parece então que as questôes concernentes ao diagnóstico desta criança, no momento em que se encontra, podem também ser discutidas do seguinte modo: o que é AAA? Qual o seu valor? Qual o seu estatuto? Ou de outro modo: que tipo de asserção teve o significante sobre o corpo dessa criança que the permite esses desdobramentos?

Responder a essas perguntas amplia a nossa condiçào de pensar a direçào clesse tratamento.

$\mathrm{Na}$ primeira emergência de AAA nada garantia que essas letras grafadas no papel tivessem um estatuto outro que nào o de uma emergência arbitrária que apontasse somente para a aquisiçào de conhecimento. Porém, para que esse par de letras fosse escrito, um longo percurso foi construído: as marcas sobre o corpo e o desenho de si são indícios deste caminho. Sabemos entào que se trata de uma emergência que se encadeia.

Sibele usa AAA para designar a si mesma, e nesse sentido essas letras constituem o significante que a representa. Mas AAA serve-lhe também para escrever outros nomes. Deste modo, e se tomarmos AAA como um significante, podemos entender que a marca de Sibele pode também designar outras coisas do mundo. Caberia aqui o seguinte apontamento: se aquele significante que emergiu como "marca própria" de Sibele pode the servir também para designar outras coisas do mundo, 
ele nào tem mais este estatuto de "marca própria". Porém podemos entender que aquilo que emergiu como "marca própria", no eixo da representaçào, é exatamente o que pode designar qualquer coisa do mundo, devido a suá especial posição na linguagem, que a situa, neste momento, como uma criança psicótica.

É possível pensar que o fato de Sibele designar a si mesma na terceira pessoa, (exemplificado na frase que constrói para pedir material a um profissional: "Cola para Sibele"), é um forte indício de que ela constrói sua identidade na posiçào de objeto, está atada no nível do enunciado, e que as suas produçoes se dào num campo especular.

Joel Dor (1995), afirma que a relação do sujeito com o significante convocado em sua nomeação é uma relação de identificação, assim, o sujeito só poderá nomear-se na medida em que se identifique com o significante puro, que é o nome próprio, pois algo da ordem do traço unário deve operar para produzir essa significação. Representar-se por AAA, para Sibele, é inaugurar uma posição de sujeito, mesmo que ainda não barrado, é uma enunciaçào que corta o plano estritamente objetal. AAA não é um atributo do objeto, é a uma emergência não especular na produção de Sibele. AAA é um significante que a representa.

Entendemos que esse AAA é fruto de uma inscrição feita no corpo dessa criança. Porém, é uma inscrição cuja possibilidade de fazer cadeia é reduzida. Jerusalinsky (1996), utiliza uma imagem bastante interessante. Formula que o elástico simbólico das inscrições recebidas por crianças psicóticas estica pouco. O trabalho que propomos para Sibele tem como ponto de partida essa inscrição marcada em seu corpo e que tem podido estender-se.

Restaria uma pergunta a respeito do fato de Sibele usar a marca AAA que a representa (esse daclo se confirma quando escreve tal marca e lê seu próprio nome) para referir-se a outras coisas do mundo. A que esta emergência remete?

Para que Sibele fosse capaz de se curvar ao sistema de pura diferença da língua, falada ou escrita, seria necessário que o significante Nome-do-Pai estivesse operando de tal maneira que permitisse que a repetiçào se processasse sob o signo da diferença e nào mais da equivalência.

É nesta direçào que nos interessa introduzir a diferença no interior da produção de Sibele. Entendemos que aquilo que a impede de escrever sobo signo da diferença é a maneira pela qual está posicionada na linguagem.

\section{UMA FESTA JUNINA...}

Maria recentemente realizou algumas mudanças concretas na família. $O$ termo "concretas" faz referência a algo que ocorre na realidade, mas que nào necessariamente, como veremos aqui, passa pelo simbólico.

Não tendo o nome do pai, Sibele é reconhecida apenas como filha de sua màe. Muito precocemente, por ocasiào do nascimento de sua filha, Maria assumiu/registrou-a tomando-a unicamente para si. O reconhecimento de que falamos aqui, não se refere apenas a aspectos legais relativos à paternidade, mas à filiação. Esta ausência de reconhecimento repercute numa ausência de simbólico para sibele, na ausência do significante Nome-do-Pai.

Maria relata um episódio significativo não só em termos do reconhecimento que se põe em jogo, mas também em termos da inclusão da palavra - ou melhor, do olhar - do pai. Enquanto costurava, as meninas come- 
çaram a fazer bandeirinhas de festa junina. Pediram barbante para a màe, e esta última deixou tudo pendurado para o marido ver. Este episódio é um marco no tratamento de sibele. O que fica confirmado pelo fato de ela retomar a construçào das bandeirinhas em diversos momentos, após muitos meses, espontaneamente. A retomada desta atividade indica não só o reconhecimento que houve ali, mas a busca deste, uma e outra vez. Avaliamos que algo da ordem de uma inscriçào ocorreu aqui. Houve também um primeiro momento de entrada deste pai como terceiro, reconhecendo esta filha. Este episódio das bandeirinhas tem seu ponto culminante com a primeira - e por ora única - visita deste pai ao Lugar de Vida, justamente alguns dias depois, por ocasiào da festa junina.

Segundo Jerusalinsky (1996), uma inscrição ocorre quando a màe diz "Não". O que determina o "Nào" da mãe é a lei à qual ela está referida: a função paterna. As crianças psicóticas recebem certa marca/inscrição - como no caso de Sibele - mas algumas vezes esta não chega muito longe, o elástico simbólico estica pouco. O trabalho realizado no Lugar de Vida consiste justamente em promover/fabricar situaçoes em que este elástico possa ir esticandose. Agora, além de receber a inscrição, é fundamental o reconhecimento dos pais, como ocorre quando Maria atribui algo da ordem do "emocional" à febre da filha. Ou ainda, quando a màe reconhece nas bandeirinhas de festa junina uma produçào e as guarda para mostrar ao pai.

Embora o pai comece a ter entrada - comece a se delinear um "lugar" do pai - e Sibele venha apresentando alguns momentos de emergência subjetiva, ainda há um longo caminho a ser traçado por essa família, principalmente na construção e delimitação dos lu- gares, o que fica ilustrado pelo seguinte ato de Maria: Ela nos conta, orgulhosa, que há agora uma cama para sibele e outra para a irmà em seu quarto (lembremo-nos de que antes nào havia espaço para outras camas neste mesmo quarto. Podemos nos perguntar: o que mudou para que agora haja espaço onde nào havia?). Trata-se de um ato, o qual revela efeitos do tratamento, efeitos que vào na direçào da discriminaçào dos lugares que cada qual ocupa nesta família. Na realidade, mais adiante, Maria conta que mesmo com uma cama para cada uma de suas filhas, as coisas continuam confusas, e sibele insiste em dormir em um cantinho de sua cama. Este ato empreendido por Maria nào foi suficiente para gerar uma mudança. Provavelmente porque se trata de uma medida concreta, que se traduz exclusivamente na realidade. Faltam aqui a intervenção e o ato simbólico. Trata-se de um desejo consciente da màe, mas não de uma resposta a um movimento inconsciente. É preciso que esta màe se pergunte sobre sua parte nisso tudo e se implique.

\section{A ESTRUTURA OSCILA}

A busca por uma forma de representar-se é acompanhada por uma diminuição ainda maior da agitação em Sibele e pela possibilidade de sentar-se e realizar uma tarefa. Agora, os olhos que vagavam sem endereço podem focalizar o outro.

Nos diversos espaços do Lugar de Vida, Sibele trabalha - como gostamos de dizer - muito. Produz e produz e produz. Solicita materiais, pede fita crepe para pendurar suas produçòes na parede e reconhece-as no dia seguinte. Observamos que produz na equipe um deslumbramento, certa seduçào, com a produçào rica e incessante - porém 
auto-centrada - que apresenta. Nesta produção, não há descontinuidade ou falta. É por isso que marcamos: produz e produz e produz. Sabemos da importância do ponto final em uma frase para que o sentido possa advir. Sabemos que o fim ressignifica o começo, e que o psicótico está posicionado na linguagem como uma frase sem um ponto final. Na realidade, queremos chamar a atenção aqui para o fato de que Sibele, apesar de movimentos preciosos e de toda a construçào significante que descrevemos acima, reproduz uma estrutura psicótica ainda em grande parte do tempo, na qual a falta é obturada, nào tem lugar. Esta reprodução é concomitante a momentos em que Sibele aciona recursos para lidar com a falta. Os episódios descritos a seguir confirmam esta alternância de posição em Sibele.

Diante da falta, ou seja, em situaçòes em que Sibele é colocada diante do "nào" ou da necessidade de espera, há momentos em que apresenta recursos - o referido elástico simbólico se estica um pouco mais. Como ocorreu no ateliê de música, no qual sibele queria que as coordenadoras trouxessem a televisão para assistir as "muiéres" (vídeo sobre bailarinas) mas acabou aceitando, após o choro e tentativas de obter o que queria, a fita com a música que havia no vídeo. Mas há também momentos em que se desorganiza, chora, e fica impossibilitada de realizar deslocamentos. Mais que isso, conforme aconteceu no ateliê Contar Histórias, na falta do que queria, Sibele aciona uma "braveza", repetindo falas da màe, ou seja, é atravessada/invadida pelo Outro materno. Ela ouve a mensagem de forma direta, é tomada pelo Outro. Ela se "veste" do Outro e fala deste lugar.

O fato de, para esta criança, alguns eventos retornarem no real, de nenhuma forma invalidam as conquistas - ainda titubeantes - no campo do simbólico. A estrutura ainda se sustenta de forma precária.

Para concluir, gostaríamos de comentar duas produçòes recentes de Sibele. Na primeira há uma menina, construída com massinha, que tem cabeça, corpo e membros, além de cabelos e rosto. Esta menina está no centro de uma folha de papel muito enfeitada na qual distribuiu muitas bolinhas coloridas, reproduziu muitas vezes sua marca/assinatura e desenhou cuidadosamente na parte superior da folha as bandeirinhas. Novamente nos aproximamos da época em que se comemora a festa junina. Mas esta não é qualquer ocasião. Sibele traz o tema e se põe a trabalhar. Na outra produçào, Sibele desenha bandeirinhas de festa junina no alto de uma folha. Na parte inferior inclui uma menina, e, em seguida, duas outras figuras, dando as màos para a menina, que ficou ao centro. Abandona o desenho e levanta-se da mesa. É convidada a sentar-se novamente e escrever. Aceita o convite, e com uma caneta - naquele desenho em que já havia uma coleçào de bandeirinhas de festa junina e três personagens - escreve A e fala bem baixinho: "pai".

Esta foi a leitura mais recente que Sibele fez da escrita da letra $A$, e que levou sua mãe a perguntar se estaríamos ensinando sibele a escrever papai.

Pensamos que ambas as cenas construídas por Sibele fazem uma síntese de seu percurso até o presente momento. Ela percorreu um longo caminho, passando pela construção de sua imagem corporal, pela extensão de uma inscrição, pela construçào de uma marca. A festa junina, ainda, remete a um primeiro momento de inserção do olhar-palavra-presença do pai.

Como vimos acima, já nos é possível afirmar, do ponto de vista diag- 
nóstico, que o significante Nome-do-Pai nào está operando, pois a repetiçào de AAA não produziu diferença no interior do sistema, o que permitiria que diferentes palavras fossem escritas sob uma marca distinta das outras. Porém, este dado não é suficiente para que afirmemos que a estrutura já se selou. Ainda não sabemos se esse pai/AAA, que Sibele escreve, e que incide no discurso da mãe, vai operar como uma Metáfora não Paterna, e funcionar como suplência para estabilizar a psicose de Sibele, ou se poderá ainda se instituir como Nome-do-Pai, operando uma mudança de estrutura.

Há ainda um certo percurso a ser traçado e atravessado por toda essa família. Faltam ainda algumas festas juninas...

\section{REFERÊNCIAS BIBLIOGRÁFICAS:}

AUBRY, J. (1986). Duas notas sobre a criança. Publicado originalmente em Ornicar? In: Revista do Campo Freudiano, n. 37. Itradução de Silmia Sobreira para uso interno da Escrita Freudiana, jun. 1986].

CORIAT, E. (1997). Psicanálise e Clínica de Bebês. Porto Alegre. Artes e Of'cios.

DOR, J. (1995). Introduçào à leitura de Lacan - estrutura do sujeito. Porto Alegre. Artes Médicas Sul.

JERUSALINSKY, A. (1993). Psicose e autismo na infância: uma questào de linguagem. In: Psicose - boletim da associação psicanalitica de Ponto Alegre, ano 4, n. 9.

JERUSALINSKY, A. (1996). Seminários proferidos no Instituto de Psicologia da USP.

KUPFER, M.C. (1997). Educação terapêutica. In: Estilos da Clinica - revista sobre a infância com problemas, ano $1, \mathrm{n}^{\circ} 2$.

LAZNIK-PENOT, M.C. (1991). O que a clinica do autismo pode ensinar aos psicanalistas. Salvador. Álgama.

STEFAN, D. (1991). Autismo e Psicose. In: $O$ que a clínica do autismo pode ensinar aos psicanalistas. Salvador. Álgama.

\section{NOTAS:}

(1) É importante ressaltar que nào estamos considerando o autismo como uma classe dentro das psicoses. A discussào dessa questào, de modo algum unânime, nào será realizada nesse trabalho.

(2) Os fragmentos grafados em itálico fazem referência a falas textuais.

(3) Para ilustrar como começa a ser delineada a transferência, introduzimos o seguinte exemplo: Maria acredita que se Sibele ficasse sentada, quicta, poderia ir para a escola. Afirma que primeiro é melhor ela vir ao Lugar de Vida, "onde se entende sobre se't problema", para depois procurar uma escola. Espera receber orientaçào no L.V. 